Review Essay

\title{
Crime, fear of crime, environment, and mental health and wellbeing: Mapping review of theories and causal pathways
}

\author{
Theo Lorenc ${ }^{\mathrm{a}, *}$, Stephen Clayton ${ }^{\mathrm{b}}$, David Neary ${ }^{\mathrm{b}}$, Margaret Whitehead ${ }^{\mathrm{b}}$, Mark Petticrew ${ }^{\mathrm{a}}$, \\ Hilary Thomson ${ }^{\mathrm{c}}$, Steven Cummins ${ }^{\mathrm{d}}$, Amanda Sowden ${ }^{\mathrm{e}}$, Adrian Renton ${ }^{\mathrm{f}}$ \\ a Department of Social and Environmental Health Research, London School of Hygiene \& Tropical Medicine, 15-17 Tavistock Place, London WC1H 9SH, UK \\ ${ }^{\mathrm{b}}$ Department of Public Health and Policy, University of Liverpool, Whelan Building, Liverpool L69 3GL, UK \\ ${ }^{\mathrm{C}}$ MRC Social and Public Health Sciences Unit, 4 Lilybank Gardens, Glasgow G12 8RZ, UK \\ d School of Geography, Queen Mary University of London, Mile End Road, London E1 4NS, UK \\ e Centre for Reviews and Dissemination, University of York, York Y010 5DD, UK \\ ${ }^{\mathrm{f}}$ Institute for Health and Human Development, University of East London, Water Lane, London E15 4LZ, UK
}

\section{A R T I C L E I N F O}

Article history:

Received 6 December 2011

Received in revised form

6 March 2012

Accepted 6 April 2012

Available online 19 April 2012

Keywords:

Crime

Fear of crime

Mental health

Wellbeing

Built environment

Review

\begin{abstract}
A B S T R A C T
This paper presents the findings from a review of the theoretical and empirical literature on the links between crime and fear of crime, the social and built environment, and health and wellbeing. A pragmatic approach was employed, with iterative stages of searching and synthesis. This produced a holistic causal framework of pathways to guide future research. The framework emphasises that crime and fear of crime may have substantial impacts on wellbeing, but the pathways are often highly indirect, mediated by environmental factors, difficult to disentangle and not always in the expected direction. The built environment, for example, may affect health via its impacts on health behaviours; via its effects on crime and fear of crime; or via the social environment. The framework also helps to identify unexpected factors which may affect intervention success, such as the risk of adverse effects from crime prevention interventions as a result of raising awareness of crime.
\end{abstract}

(c) 2012 Elsevier Ltd. All rights reserved.

\section{Background}

Crime and the fear of crime have been identified as potential mediators between neighbourhood characteristics and mental health and wellbeing outcomes (Jenkins et al., 2008), as promising loci of interventions to improve wellbeing (Department of Health, 2010; Department of Health, 2011), and as important dimensions of wellbeing in their own right (Stiglitz et al., 2009). Similarly, theories of the determinants of mental health have focused on crime as a major explanatory factor: for example, the VicHealth framework in Australia includes 'freedom from discrimination and violence' as one of the three key determinants of mental health, along with social inclusion and economic participation (Herrman et al., 2005; Keleher and Armstrong, 2005). In addition, participatory research has identified crime and antisocial behaviour as an

\footnotetext{
* Corresponding author. Tel.: +442079272778.

E-mail addresses: theo.lorenc@lshtm.ac.uk (T. Lorenc), stephen.clayton@liverpool.ac.uk (S. Clayton), david.neary@liverpool.ac.uk (D. Neary),mmw@liverpool.ac.uk (M. Whitehead), mark.petticrew@lshtm.ac.uk (M. Petticrew), hilary@sphsu.mrc.ac.uk (H. Thomson), s.c.j.cummins@qmul.ac.uk (S. Cummins), ajs18@york.ac.uk (A. Sowden), a.renton@uel.ac.uk (A. Renton).
}

important influence on wellbeing (Burke et al., 2009; O'Campo et al., 2009).

Thus, crime and fear of crime are widely recognised as potentially important influences on mental health and wellbeing. They also exemplify the kinds of complex environmental factors which may only be partially illuminated by quantitative observational studies alone (Cooper et al., 2008). Synthesising and understanding the complex links between physical environmental mechanisms, social norms and imagery, and simultaneously incorporating the impact of distal factors which cannot be captured in a linear concept of causality, demands a flexible approach which can integrate heterogeneous types of evidence (Cummins et al., 2007). Investigating such links also demands the integration of research from a range of disciplines, not only those directly related to health and wellbeing.

The primary aim of this paper is to present a holistic framework tracing the theoretical links between crime, fear of crime, the environment and health and wellbeing. The framework presented here was developed as part of a broader evidence synthesis project, which will include systematic reviews of the effectiveness of interventions in the built environment to improve health and wellbeing through addressing crime or the fear of crime, and of qualitative evidence relating to fear of crime and the 
built environment. Within this context, the framework is designed to facilitate an understanding of the contexts within which policy-makers and practitioners might seek to improve health and wellbeing by addressing crime and fear of crime.

A secondary aim is to use the framework as a methodological case study, to illustrate one possible way of constructing theory in the context of undertaking evidence synthesis of the effectiveness of complex social interventions. The value of theory-led approaches, particularly those that generate causal pathway frameworks, is now widely acknowledged (Anderson et al., 2011; Craig et al., 2008). However, in relatively few cases have such frameworks been set out in detail, supported by a discussion of underlying theories and empirical evidence. Previous research has emphasised a 'logic model' approach which is limited to elucidating the internal pathways of interventions, and does not lend itself either to a broader contextualisation of interventions, or to a critical engagement with the theories they embody. The approach set out below represents an attempt to remedy some of these limitations. Thus, this paper may also be seen in the context of the ongoing debate about the role of theory in informing systematic reviews, particularly reviews of complex interventions.

\section{Methods}

We employed a pragmatic approach, with iterative stages of searching and synthesis, influenced by realist review (Pawson et al., 2004), critical interpretive synthesis (Dixon-Woods et al., 2004, 2006) and the causal mapping method of Baxter et al. (2010). The aim was to generate a framework incorporating relevant theories and evidence on pathways to guide the broader project.

The construction of the framework took place in three phases within the overall iterative process. The initial phase attempted to catalogue the main theories linking the central concepts of crime, fear and crime and health and wellbeing, and develop a metatheoretical framework to integrate them. Many of these theories were found to draw upon broader concepts (the physical and social environment, and policy-level factors) which were then included in the framework in their own right. This then induced a second phase in which the theoretical links between these further concepts and the original foci of interest were explored. Finally, where the theoretical literature was not directly based on empirical findings, we carried out further targeted searches to locate empirical evidence on the associations posited by the theories.

Search sources included targeted database searches and suggestions from subject experts within the review team and the Advisory Group; there was also a strong emphasis on 'pearl growing' methods such as citation chasing. The selection of studies prioritised those which helped to shape the emerging meta-theoretical constructs, and was initially pursued to the point of theoretical saturation with respect to the framework. Where the theories were conflicting or underdetermined, further searches were undertaken to identify empirical studies reporting data and associations between variables relevant to the theory, with a view to at least an indicative judgement of the theoretical claims. Thus, the main foci in terms of data were theoretical literature and quantitative observational studies of associations between variables, although we also utilised qualitative evidence, outcome evaluations, policy papers and a range of other types of evidence.

\section{Results}

Fig. 1 provides a graphical overview of the model derived from our review, showing the six key conceptual areas identified and the potential links between them.

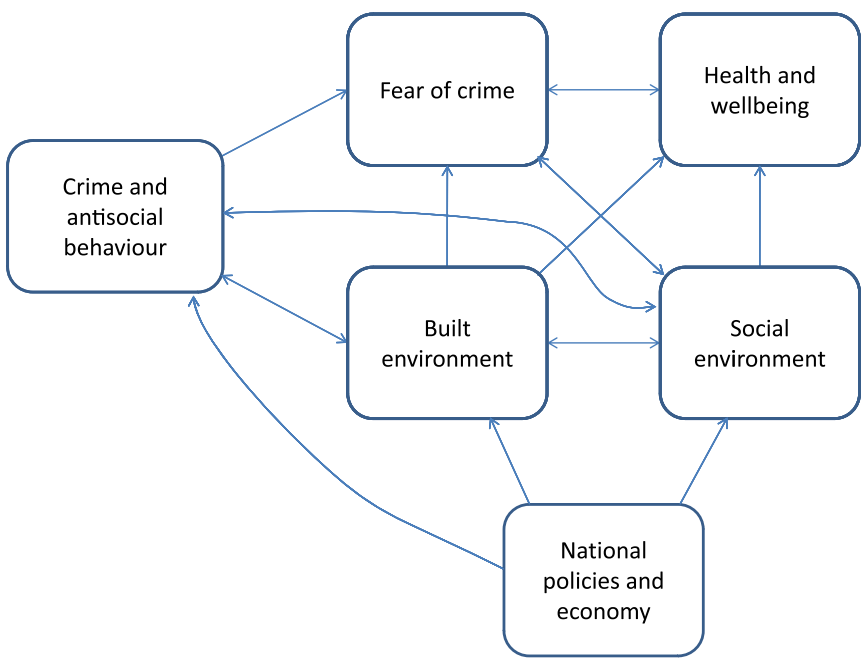

Fig. 1. Overview theoretical model

Fig. 2 presents the more detailed model, in which the six main areas are disaggregated into sub-concepts (with some areas of overlap) and the links set out in more depth. The main areas are shown as large hollow boxes, the sub-concepts as smaller shaded boxes, and the links as arrows.

The main concepts and sub-concepts are as follows.

- 'Crime and disorder' includes all types of crime and antisocial behaviour;

- 'Fear of crime' includes two main dimensions: the perceived likelihood of victimisation (the cognitive dimension) and the emotional response to the possibility of crime (the affective dimension);

- 'Health and wellbeing' is an inclusive concept including physical and mental health outcomes, health behaviours, and social wellbeing;

- 'Built environment' includes all factors relating to the physical environment insofar as they are shaped by human activity;

- 'Social environment' has been conceptualised on the basis of a previous review of theories (McNeill et al., 2006), and includes social inequalities and interpersonal networks, as well as the distribution of social factors in space ("neighbourhood and community factors'), which overlaps with the built environment; and

- 'National policies and economic factors' includes all broader policy or economic factors which may have an impact on crime or fear.

Due to limited space and resources, not all of the potential links identified in Fig. 1 have been dealt with in detail in the review. In particular, we have excluded the social, political and economic causes of crime from our scope (i.e. the links going from the social environment and national policy to crime). In addition, we have not considered the policy-level determinants of other factors in any detail; national policy is included in the framework mainly as a reminder that all the factors are shaped directly or indirectly by macro-level determinants. These limitations of scope should be borne in mind in interpreting the framework.

In the following sections we discuss the links between these concepts and their sub-concepts.

\subsection{Crime, health and wellbeing}

Crime may influence health in a range of ways (Hirschfield, 2004). A distinction can be made between direct and indirect 


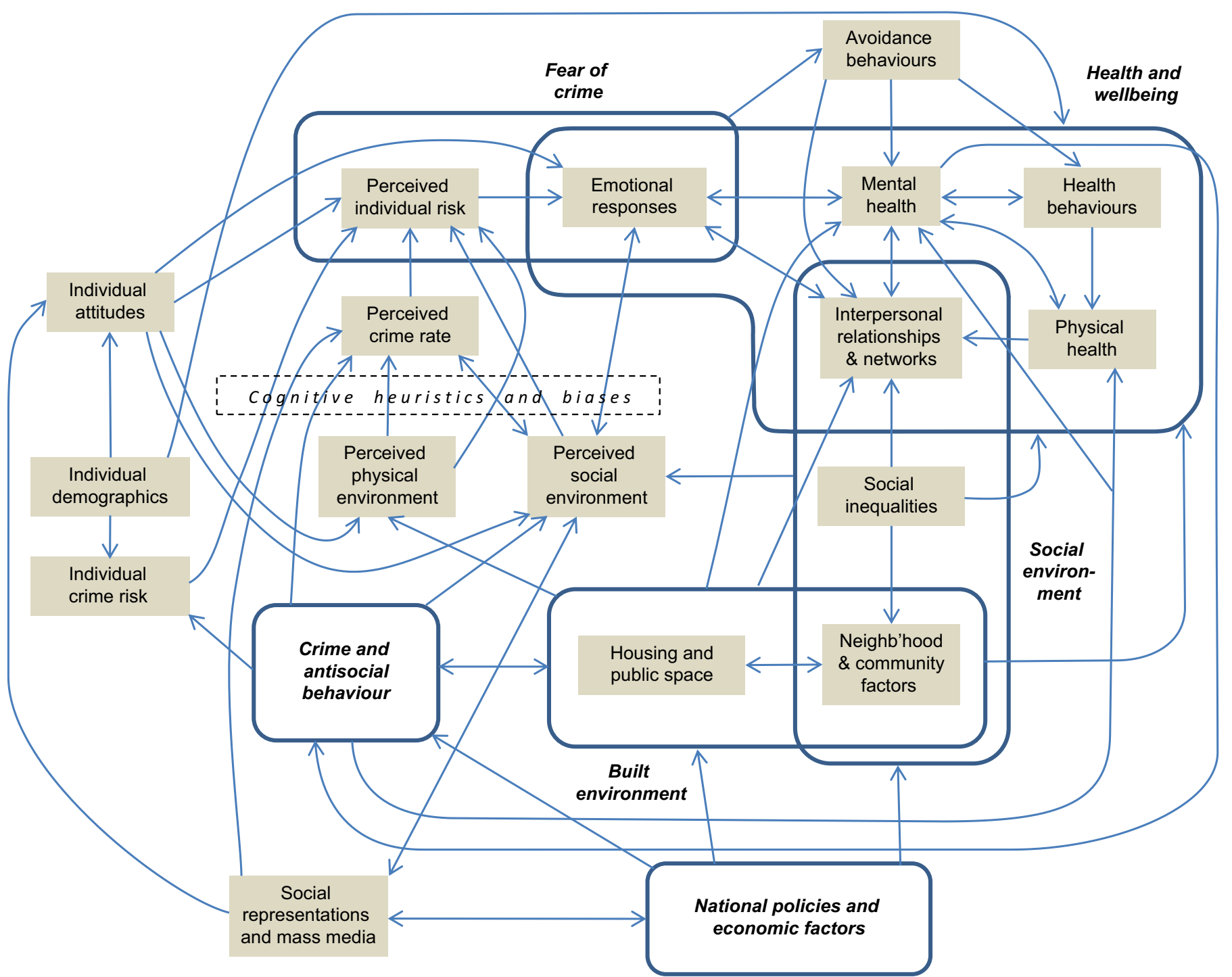

Fig. 2. Detailed theoretical model

impacts (McManus and Mullett, 2001). Direct impacts include both physical injuries and psychological trauma as a result of being victimised. Most direct impacts arise from violent crimes against the person (although non-violent crimes such as burglary may also have direct psychological impacts on victims). These direct impacts are represented in the framework by the link from crime to physical and mental health. Indirect impacts include a wide range of negative effects which crime can have on wellbeing at an ecological level, apart from its direct effects on victims. Most of these effects are likely to operate mainly at neighbourhood level, and are represented in the framework as several distinct pathways linking crime and wellbeing via physical and social environments, the perceived environment, and fear of crime.

The direct impacts of personal victimisation, particularly of serious and violent crime, on individual victims' health have been the focus of most studies of crime and health (McCabe and Wine, 1997; McManus and Mullett, 2001; Robinson and Keithley, 2000). A substantial body of literature documents these direct physical and mental health impacts on victims, which are often substantial and long-lasting, and unequally distributed across the population (see for example Norris and Kaniasty, 1994; Russo and Roccato, 2010). 'Domestic' crimes, including child abuse and intimate partner violence, may have particularly serious health impacts
(Campbell, 2002; Coker et al., 2002; Fanslow and Robinson, 2004). The significance of these direct impacts at a population level is unclear. Violent crimes occur relatively rarely-approximately 40 incidents per 1000 people per year in England and Wales (Home Office, 2012) — so the impact of their direct effects on the health of the general population is likely to be limited. However, due to the unequal distribution of crime, the impact on certain groups may be greater.

The indirect impacts of neighbourhood crime on health and wellbeing are more complex in nature. Area-level violent crime has been found to be associated with a range of negative health status outcomes, including all-cause mortality (Wilkinson et al., 1998), coronary heart disease (Sundquist et al., 2006), and preterm birth and low birth weight (Messer et al., 2006), as well as with health behaviours such as lower physical activity (Gómez et al., 2004; McDonald, 2008). Exposure to violence in the areas in which people live is also known to be associated with poorer physical and psychological health, particularly for children and young people (Boynton-Jarrett et al., 2008; Fowler et al., 2009). However, although these associations are well-established, the causal pathways involved remain open to debate. One mechanism which has been of interest to sociological researchers is the diffuse effect of structural inequality and disadvantage in conjunction with 
repeated victimisation or the threat of victimisation. Such 'latent' structural violence may particularly affect women, people from ethnic minorities and people of lower socio-economic status, and has been encapsulated in the concept of 'spirit injury' (Walklate, 2007; Spalek, 2008).

Health itself may also have an impact on crime: people with health problems, particularly serious mental health problems, may be at greater risk of being the victims of crime (Choe et al., 2008; Maniglio, 2009; Teplin et al., 2005). This is represented in the model by the pathway from mental health to crime.

Finally, health behaviours are also included as a dimension of wellbeing in the model, and may themselves be linked to crime. Alcohol consumption is of particular interest here. At an individual level, problem drinking is known to be associated with violent offending (Shepherd, 2007); at an area level, alcohol outlet density is associated with alcohol consumption and related harms, including injuries and violence (Campbell et al., 2009; Popova et al., 2009). However, as in the example above, the direction of the causal relationships underlying these associations are not entirely clear.

\subsection{Fear of crime and health and wellbeing}

The framework includes four potential pathways connecting fear of crime to health and wellbeing outcomes.

(1) The anxieties induced or expressed by fear of crime may have an impact on mental health, and indeed may be considered a wellbeing outcome in themselves.

(2) Poorer health, particularly mental health, may exacerbate fear of crime.

(3) Fear of crime may lead to avoidance behaviours such as limiting one's movement outside the home, which may have a negative impact on (a) social interaction and (b) physical activity.

(4) Fear of crime may have an impact on social wellbeing at an ecological level.

Pathways 1 and 2 are difficult to disentangle empirically, as they link the same types of outcomes in opposite directions. The link itself is fairly well-established: several studies have found that affective measures of fear of crime are associated with poorer mental and physical health, although effect sizes are generally modest (Beatty et al., 2005; Chandola, 2001; Green et al., 2002; Roberts et al., 2010; Ross, 1993; Ross and Mirowsky, 2001; Stafford et al., 2007). There is also some evidence of an association between cognitive measures (perceived crime or risk of crime) and poorer health outcomes (Kitchen and Williams, 2010; White et al., 1987), although the findings here are less consistent, and other studies find no association (Bowling et al., 2006; Johnson et al., 2009).

However, while pathway 1 is likely to account for at least some of this association, pathway 2 may also have some effect, in that poor health, particularly mental health, may increase perceived vulnerability and hence fear of crime (Whitley and Prince, 2005). People in poor health have been found to be much more likely to report that fear of crime has a high impact on their quality of life: $20 \%$ for those with 'bad' or 'very bad' health, compared to 5\% for the general population (Allen, 2006). Whereas much fear of crime, as measured by standard instruments, appears to be benign and 'functional' (Jackson and Gray, 2010), people with mental health problems are disproportionately likely to experience fear which has a substantial impact on wellbeing (Whitley and Prince, 2005). This has implications for the planning of interventions: if pathway 2 rather than pathway 1 explains much of the observed association between fear of crime and health, then reducing crime and the fear of crime may have limited potential to improve health and wellbeing. This said, longitudinal data suggests that pathway 1 does have a significant impact independently of pathway 2 (Stafford et al., 2007). Rather than simply coexisting with pathway 1 , pathway 2 may interact with it, in a vicious circle or 'feedback loop' between fear of crime and ill-health (Jackson and Stafford, 2009).

Pathway 3 links fear of crime to wellbeing via the avoidance behaviours adopted to lessen the perceived risk of victimisation. Many of these are everyday precautions which are likely to have little impact on wellbeing (e.g. locking doors). However, others may limit individuals' activities to a considerable extent, as they reorganise their lifestyles to avoid areas or activities perceived as involving exposure to risk. For women particularly, extensive constraints on behaviour resulting from fear may become internalised and normalised as an attitude of constant vigilance, with pervasive and potentially serious consequences for wellbeing (Campbell, 2005; Condon et al., 2005; Pain, 1997, 2000; Stanko, 1997).

These avoidance behaviours may be linked to health and wellbeing outcomes in two ways. First (pathway 3a), avoidance behaviours may limit interpersonal interaction, leading to poorer mental health (Stafford et al., 2007). Again, there may be a feedback loop here whereby limiting social interaction also increases fear in its turn (Liska et al., 1988). Second (pathway $3 \mathrm{~b}$ ), they may limit outdoor physical activity, hence leading to poorer physical health. This pathway has received considerable attention in the theoretical literature (Loukaitou-Sideris and Eck, 2007), although the empirical findings are mixed (Carver et al., 2008; Foster and Giles-Corti, 2008).

Pathway 4 hypothesises that fear of crime leads to decreased trust and cohesion within communities and to individual withdrawal, with a series of feedback loops at ecological and policy levels leading to progressive decline in social and physical environments, which then impact negatively on wellbeing (Skogan, 1986; Vanderveen, 2006). This can be seen as an extended loop which goes from fear of crime to interpersonal relationships, and from there (as part of the social environment) directly and/or via the built environment to the perceived environment and back to fear of crime. However, while this pathway has received considerable theoretical attention, many of the posited links are difficult to substantiate empirically.

Of the seven studies of associations between fear of crime and health cited above, two attempt to quantify the relative importance of these pathways. Ross (1993) investigates psychological distress (pathway 1) and physical activity (pathway 3b), and Stafford et al. (2007) physical activity (pathway 3b) and social interaction (pathway 3a), as potential mediators. Both find that a substantial amount of the association is explained by these pathways, but not all. This may indicate that broader, more diffuse connections, such as those hypothesised in pathway 4 , play a role in the health and wellbeing impacts of fear of crime.

\subsection{Crime and fear of crime}

The link between crime and fear of crime is more complex than it may initially seem. This is partly because the concept of fear of crime is beset by issues of definition and measurement. It has been widely argued that standard measures of fear of crime tend to reflect general anxiety or unease, or broader perceptions of the social and physical environment, rather than anything specifically to do with crime (Farrall et al., 1997; Garofalo and Laub, 1978; Taylor and Jamieson, 1998). Empirical studies have generally found little relation between objectively measured probability of victimisation, or even actual experience of victimisation, and individuals 
fear or estimates of their own risk (Farrall et al., 2007; Hale, 1996).

Thus, there does not appear to be a reliable direct link between crime and fear of crime (the so-called 'risk-fear paradox' (Farrall et al., 2007)). Two implications may be drawn from this. The first is that fear of crime may be driven less by crime itself than by factors such as the physical environment or interpersonal relationships; these theories are examined in the following sections. The second, going back to the classic work of Tversky and Kahneman (1974), is that the link between crime and fear may be influenced by various biases and pragmatic procedures for estimating risk ('cognitive heuristics') which lead to inaccurate assessments of risk. For example, the 'anchoring and adjustment' heuristic involves using a single piece of information as an 'anchor' for estimates of risk and 'adjust' other information to fit. This may help to explain the finding that most people think crime is much worse at a national level than in their local area: media coverage of serious violent crime forms the anchor for estimates of risk, and people's direct experience of less serious, more high-volume crimes is adjusted accordingly (Moon et al. 2009). Such heuristics may also explain the potential for intensive policing interventions to increase fear by raising awareness of crime (Hinkle and Weisburd, 2008). They may act on a social as well as an individual level through the 'social amplification of risk' (Jackson, 2006; Pidgeon and Kasperson, 2003); the mass media may be particularly important here, although individual media consumption does not appear to be strongly associated with fear of crime (Chadee and Ditton, 2005; Ditton et al., 2004).

More broadly, the distinction between 'rational' and 'irrational' or 'symbolic' fear which underlies much work on the crime-fear relation (Elchardus et al., 2008) has been criticised as inadequate for understanding the place of fear in individuals' lives (Jackson, 2009; Lupton and Tulloch, 1999; Sparks, 1992). In particular, the concept of 'spirit injury' mentioned above indicates the inadequacy of labelling as 'irrational' any fear driven by factors other than the incidence of crime. For example, women's fear of rape appears to be substantially influenced by the experience of dayto-day sexual harassment, threats, and relatively minor sexual crimes such as indecent exposure (Valentine, 1989). It is thus considerably more grounded in reality than the simplistic juxtaposition with 'objective' risk of rape would suggest.

\subsection{Built environment and health and wellbeing}

The main theoretical frameworks linking factors in the built environment to health and wellbeing invoke some form of environmental stress theory, which sees wellbeing as determined by the balance between environmental stressors, such as noise, traffic, poor housing, or overcrowding, and countervailing protective factors, such as social integration (Halpern, 1995; Northridge et al., 2003). Such theories are well-supported by empirical studies of associations between these stressors and mental health outcomes (Evans, 2003; Halpern, 1995).

Crime and the threat of crime can readily be integrated into this type of theory as part of the complex of environmental stressors (Ellaway and Macintyre, 1998). The environmental stress concept is thus a useful framework for thinking about crime and fear of crime as mediators between environmental determinants and health outcomes. In addition, it supports the idea that the cumulative effect of everyday stress and anxiety can have a substantial effect on wellbeing-analogous to Arline Geronimus' 'weathering hypothesis' (Geronimus, 1992; Geronimus et al. 2006) — which helps to fill out the broader picture of the impacts of crime beyond its direct physical effects on victims.

The framework represents the potential influences of the built environment on health in terms of three main pathways. The built environment may affect health via its impacts on health behaviours (Humpel et al., 2002; Saelens and Handy, 2008); via its effects on crime or fear of crime; or via the social environment.

\subsection{Built environment and crime}

A range of features of the built environment have been hypothesised to have an impact on crime rates. The majority of the literature on these impacts focuses on identifying features of the built environment that provide opportunities for criminal acts, which may then be adjusted to reduce or prevent crime (Robinson, 1999). Some of these theories have adopted a distinction between 'crime science', which emphasises situational opportunities for crime, and (traditional) criminology, which focuses more on the social, economic and political determinants of crime.

Several strategies in the built environment have been shown by high-quality systematic reviews to be effective in reducing crime, including improved street lighting (Welsh and Farrington, $2008 \mathrm{~b}$ ) and, in a limited range of contexts, closed-circuit television (Welsh and Farrington, 2008a). Environmental design approaches are effective in reducing robberies in retail settings (Casteel and Peek-Asa, 2000), although there is little robust data on such approaches in residential or community settings (Eck, 1998).

The most influential theoretical paradigm has been Crime Prevention Through Environmental Design or CPTED. CPTED emphasises three key concepts as mediators between the physical environment and crime and other negative outcomes: ownership or territoriality; surveillance; and access control (Cozens et al., 2001; Robinson, 1999). CPTED theorists recommend specific design practices to increase these mediators, for example, clearly demarcating public from private space, and removing visible signs of neglect (litter, graffiti, etc.), to promote territoriality (Taylor, 2002); improving visibility to increase surveillance; and limiting points of entry to control access.

CPTED has been widely influential among policy-makers, particularly in the USA and the UK, and has been incorporated into initiatives such as Secured by Design, which recommends the integration of crime prevention into the planning process (Armitage, 2004). However, CPTED has been criticised for focusing on local-level initiatives which may merely displace crime to other areas (Cozens et al., 2005); for focusing on public outdoor spaces to the neglect of private or domestic spaces (Davies, 2008); and for encouraging a 'bunker mentality,' leading to reduced social cohesion as communities withdraw behind the barriers of ‘defensible space' (Cozens et al., 2005).

In addition, there is limited empirical support for many of CPTED's more distinctive claims about territoriality and surveillance (although the potential for interventions in the built environment to reduce crime is well established in general). Much of the empirical literature on built-environment factors and crime (reviewed in Schneider and Kitchen, 2007) consists of cross-sectional observational studies with inadequate controlling for confounders, and systematic reviews are lacking, so the reliability of this literature is limited. However, more recent and methodologically sophisticated research, particularly using the 'space syntax' approach to model social interactions in space, has reported some promising results which may validate some of the predictions of the theory (Hillier and Sahbaz, 2007; Friedrich et al., 2009).

3.6. Built environment, social environment, national policy and fear of crime

The built and social environment may have an impact on crime rates, and the latter on fear of crime. In this sense, the environment 
may have an impact on fear indirectly, by providing information about crime rates, which individuals then build into their risk perceptions. However, as we have seen, fear of crime may also express broader dissatisfactions with the environment. Hence, the environment may impact on fear of crime directly, independently of its effects on crime, by inducing feelings of threat, anxiety or alienation which are expressed as fear.

Two main theoretical approaches to the impacts of the environment on fear of crime can be found in the literature (Crank et al., 2003; European Crime Prevention Network, 2004; Franklin et al., 2008; Kanan and Pruitt, 2002; Vanderveen, 2006). 'Incivilities theory' or 'social disorder theory' emphasises the role of subcriminal but antisocial activities in the local environment, and of evidence of neglect and decay, in the genesis of fear of crime. The concept of 'incivilities' here includes both problems in the built environment, such as vandalism and abandoned properties, and problems in the social environment, such as people dealing or using drugs. (The term 'broken windows', introduced by Wilson and Kelling (1982), has often been used as an umbrella term for such approaches, although it has taken on other connotations in its convergence with 'zero tolerance' policing (Harcourt and Ludwig, 2006).) 'Social integration theory' emphasises the role of local-level social networks as determinants of fear. To these two we can add CPTED theory, whose hypotheses about the influence of the environment on crime have often been extended to claims about the influence of the environment on fear of crime.

Incivilities theories appear to be fairly well-supported by observational data, which show a consistent association between perceived social and physical incivilities and perceived risk or fear of crime (Box et al., 1988; LaGrange et al., 1992; Lewis and Maxfield, 1980; Perkins and Taylor, 1996; Robinson et al., 2003; Scarborough et al., 2010; Wyant, 2008). Some findings indicate that incivilities are more strongly associated with the cognitive dimension of fear (perceived risk) than the affective dimension (LaGrange et al., 1992; Rountree and Land, 1996), and more strongly with fear of property crime than with fear of personal crime (LaGrange et al., 1992).

However, other research indicates that an individual's perception of social and physical disorder is a better predictor of their fear than objectively assessed measures of these problems (Taylor, 1995; Taylor and Hale, 1986). This finding has suggested to some researchers that the observed association between disorder and fear may result less from individuals' using disorder as an indicator of risk than from the social meanings of environmental conditions (Curtis, 2010), such that their relation is more an 'expressive' link than a cause-effect relationship (Hope and Hough, 1988).

Social integration theory is less well-supported; indeed, even the predictions to be drawn from it are ambiguous. Some researchers suggest that fear of crime may be mitigated by social support, while others argue that higher social interaction may increase fear of crime by increasing communication about crime (Skogan, 1986). The empirical literature does not suggest a relationship in either direction (although such a relationship may be obscured by the heterogeneity of the outcome measures used). Some studies find an association between stronger social interaction or cohesion and lower fear of crime (Gibson et al., 2002; Riger et al., 1981; Scarborough et al., 2010). However, many studies find no consistent association (Clarke and Lewis, 1982; Green et al., 2002; Kanan and Pruitt, 2002; Roman and Chalfin, 2008; Ross and Jang, 2000; Sacco, 1993; Shields et al., 2003).

CPTED-type theories of the determinants of fear are also not fully confirmed by the data. For example, CPTED theory predicts that larger building size will be associated with lower 'territoriality,' and hence with higher fear, but the empirical findings are mixed (Newman and Franck, 1982; Normoyle and Foley, 1988).
Finally, although few data were located on policy-level determinants of fear of crime, one study finds that more generous social welfare policies are associated with higher levels of perceived safety (Hummelsheim et al., 2011).

\section{Conclusions}

This review illustrates the multiple and complex nature of the theoretical links between crime, fear of crime, the environment and health and wellbeing. It is well-established that crime has substantial direct health and wellbeing impacts on individual victims. Indirect area-level links between crime and health, for example through the effects of chronically high crime rates on social relationships, are less well established. Crime may be influenced by the physical environment, although limited robust evidence is available. Fear of crime appears to have a modest adverse effect on wellbeing, and on health behaviours such as physical activity. Fear of crime may be substantially influenced by physical environmental factors, such as neglected and run-down environments; its relation to the social environment is less clear. The concept of fear of crime is unclear, and the validity of many commonly used quantitative measures is widely questioned; it appears to be only loosely related to crime.

Although substantial bodies of theory and evidence exist in many of the subfields included in the framework, this paper reports what we think is the first attempt to produce a synthesis of the diverse literatures to provide an overarching representation of the theoretical pathways between the environment, crime, fear of crime, and health and wellbeing. Our review also indicates several areas in which systematic reviews would be of value, particularly the association between fear of crime and health outcomes; and built-environment correlates of crime and fear of crime. However, any such work would need to take into account the methodological challenges of synthesising evidence on the fear of crime, particularly the questionable reliability of many standard measures.

The review has certain limitations, resulting both from the methodology adopted and from the nature of the underlying evidence. The review did not employ formal systematic review methods, and the methods employed were open to bias in terms of both the selection and interpretation of the underlying data. A wide range of material was used to construct the framework, from broad, abstract theory to quantitative studies of specific associations, and different areas vary widely in terms of the nature of the evidence supporting them. Within fear of crime research in particular, we can distinguish between a more positivist tradition which is reliant on quantitative evidence, and a more critical tradition, based primarily on qualitative research and incorporating insights from critical and feminist sociology; these have long been distinct paradigms, and only relatively recently have researchers tried to draw them together (e.g. Farrall et al., 2009). In several cases, especially with respect to the purported 'risk-fear paradox', these paradigms may not only generate conflicting findings and narratives, but disagree fundamentally on the very nature of the phenomena to be examined.

As noted above, this review could not encompass all relevant factors. In particular, the framework does not cover the social, economic and political determinants of crime. In addition, a number of areas are covered only in summary terms, and would benefit from more detailed investigation, for example, the interactions between different dimensions of wellbeing, and the psychological mechanisms underlying judgements about and affective reactions to the environment. 
Another recurring issue is the difficulty of establishing the directionality of causal relationships from theories and observational data alone. In particular, further work on the relation between fear of crime and mental health along the lines of Stafford et al. (2007) would be valuable. Finally, while the graphical representation of the model is a useful tool to communicate the findings, it should not be taken too literally; in particular, the impression that the various concepts are discrete and well-defined, and the links between them homogenous, may be misleading.

We can tentatively propose the following more distal causal pathways linking crime and the fear of crime, and their environmental cues, to health and wellbeing. First, crime and fear of crime may have a substantial impact on wellbeing for certain groups within the population, such as people with mental health problems. Second, fear of crime is linked to health outcomes at an ecological level as part of a wider complex of environmental stressors. Third, fear of crime measures may express broader dissatisfaction with the environment.

However, in a number of areas there is less evidence for causal linkages. Generally, there appears to be limited reason to think that crime or the fear of crime, taken in isolation, are major determinants of health or wellbeing outcomes (or mediators of environmental determinants) for the general population at an ecological level. In particular, it is hard to establish pathways from crime to health outcomes, for several reasons: pathways via fear of crime are subject to considerable uncertainty; direct health impacts on victims of crime, while often serious for individuals, appear to be of limited importance at population level, due to the relatively low incidence of serious violent crime; and the strong correlation of both types of outcome with material disadvantage makes it difficult to test hypotheses about specific independent pathways between crime and health.

The potential implications for interventions are, therefore, also mixed. The framework suggests that interventions in the physical environment which reduce the fear of crime may have some beneficial impacts on health and wellbeing at a population level. Several different wellbeing dimensions might show positive impacts of such interventions, including mental health, health behaviours, and social relationships. The potential for environmental interventions which focus on crime prevention to improve wellbeing is less clear, and there is some possibility of negative effects if interventions increase awareness of crime, and hence fear. The framework suggests that interventions which integrate crime reduction into a broader set of objectives, and address other environmental determinants of wellbeing, are more likely to positively influence wellbeing outcomes. However, a robust systematic review of empirical data is required to confirm this hypothesis.

More generally, the potential challenges which the framework identifies for interventions in the physical environment indicate that other factors may be more promising loci of intervention. In particular, addressing determinants of crime in the social environment or at the policy level may be a more effective way to improve wellbeing. However, this lies beyond the scope of the present review.

On a methodological level, the work described in this paper indicates the feasibility and value of undertaking a wide-ranging exercise in meta-theory construction, based on a disparate body of theories and evidence, in order to inform evidence syntheses of complex social interventions. As has been claimed for 'logic model' approaches in general, the framework promotes an understanding of the internal mechanisms of interventions. However, the approach outlined here goes beyond this to provide an outline of the broader context within which interventions take place, and hence helps to identify unexpected factors which may affect intervention success. For example, it illustrates the risk of adverse effects from crime prevention interventions as a result of raising awareness of crime. Finally, it provides a conceptual vocabulary which can translate between divergent constructs, and hence may assist in producing a coherent synthesis of evidence on a wide range of interventions.

\section{Acknowledgements}

This project was funded by the National Institute of Health Research (Grant no. 09/3000/14). The views expressed are those of the authors and do not necessarily reflect those of the NIHR. We would like to thank the members of the project Advisory Group (Allan Brimicombe, John Middleton, James Thomas, Rachel Tuffin and Sandra Walklate).

\section{References}

Allen, J., 2006. Worry about crime in England and Wales: Findings from the 2003/ 04 and 2004/05 British Crime Survey. Home Office, London.

Anderson, L.M., Petticrew, M., Rehfuess, E., Armstrong, R., Ueffing, E., Baker, P., Francis, D., Tugwell, P., 2011. Using logic models to capture complexity in systematic reviews. Research Synthesis Methods 2, 33-42.

Armitage, R., 2004. Secured by Design: An Investigation of its History, Development and Future Role in Crime Reduction. Ph.D. Thesis. University of Huddersfield.

Baxter, S., Killoran, A., Kelly, M.P., Goyder, E., 2010. Synthesizing diverse evidence: the use of primary qualitative data analysis methods and logic models in public health reviews. Public Health 124, 99-106.

Beatty, C., Dibbens, C., Goyder, E., Grimsley, M., Manning, J., Peters, J., Wilson, I., 2005. Health of NDC Residents: Who Has the Most to Gain? Centre for Regional Economic and Social Research, Sheffield Hallam University, Sheffield.

Bowling, A., Barber, J., Morris, R., Ebrahim, S., 2006. Do perceptions of neighbourhood environment influence health? Baseline findings from a British survey of aging. Journal of Epidemiology and Community Health 60, 476-483.

Box, S., Hale, C., Andrews, G., 1988. Explaining fear of crime. British Journal of Criminology 28, 340-356.

Boynton-Jarrett, R., Ryan, L.M., Berkman, L.F., Wright, R.J., 2008. Cumulative violence exposure and self-rated health: longitudinal study of adolescents in the United States. Pediatrics 122, 961-970.

Burke, J., O'Campo, P., Salmon, C., Walker, R., 2009. Pathways connecting neighborhood influences and mental well-being: socioeconomic position and gender differences. Social Science and Medicine 68, 1294-1304.

Campbell, A., 2005. Keeping the 'lady' safe: the regulation of femininity through crime prevention literature. Critical Criminology 13, 119-140.

Campbell, C.A., Hahn, R.A., Elder, R., Brewer, R., Chattopadhyay, S., Fielding, J., Naimi, T.S., Toomey, T. Lawrence, B., Middleton, J.C., 2009. The effectiveness of limiting alcohol outlet density as a means of reducing excessive alcohol consumption and alcohol-related harms. American Journal of Preventive Medicine 37, 556-569.

Campbell, J.C., 2002. Health consequences of intimate partner violence. Lancet 359, 1331-1336.

Carver, A., Timperio, A., Crawford, D., 2008. Playing it safe: the influence of neighbourhood safety on children's physical activity. A review. Health and Place 14, 217-227.

Casteel, C., Peek-Asa, C., 2000. Effectiveness of crime prevention through environmental design (CPTED) in reducing robberies. American Journal of Preventive Medicine 18, 99-115.

Chadee, D., Ditton, J., 2005. Fear of crime and the media: assessing the lack of relationship. Crime, Media, Culture 1, 322-332.

Chandola, T., 2001. The fear of crime and area differences in health. Health and Place 7, 105-116.

Choe, J.Y., Teplin, L.A., Abram, K.M., 2008. Perpetration of violence, violent victimization, and severe mental illness: balancing public health concerns. Psychiatric Services 59, 153-164.

Clarke, A.H., Lewis, M.J., 1982. Fear of crime among the elderly: an exploratory study. British Journal of Criminology 22, 49-62.

Coker, A.L., Davis, K.E., Arias, I., Desai, S., Sanderson, M., Brandt, H.M., Smith, P.H., 2002. Physical and mental health effects of intimate partner violence for men and women. American Journal of Preventive Medicine 23, 260-268.

Condon, S., Lieber, M., Maillochon, F., 2005. Insécurité dans les espaces publics: comprendre les peurs féminines. Revue française de sociologie 46, 265-294.

Cooper, R., Boyko, C., Codinhoto, R., 2008. State-of-Science Review: SR-DR2. The Effect of the Physical Environment on Mental Wellbeing, Mental Capital and Wellbeing: Making the Most of Ourselves in the 21st Century. The Government Office for Science, London.

Cozens, P., Hillier, D., Prescott, G., 2001. Crime and the design of residential property-exploring the theoretical background-Part 1. Property Management 19, 136-164. 
Cozens, P., Saville, G., Hillier, D., 2005. Crime prevention through environmental design (CPTED): a review and modern bibliography. Property Management 23, 328-356.

Craig, P., Dieppe, P., Macintyre, S., Michie, S., Nazareth, I., Petticrew, M., 2008. Developing and evaluating complex interventions: the new Medical Research Council guidance. BMJ 337, a1655.

Crank, J.P., Giacomazzi, A., Heck, C., 2003. Fear of crime in a nonurban setting. Journal of Criminal Justice 31, 249-263.

Cummins, S., Curtis, S., Diez-Roux, A.V., Macintyre, S., 2007. Understanding and representing 'place' in health research: a relational approach. Social Science and Medicine 65, 1825-1838.

Curtis, S., 2010. Space, Place and Mental Health. Ashgate, Farnham.

Davies, P., 2008. Looking out a broken old window: community safety, gendered crimes and victimizations. Crime Prevention and Community Safety 10, 207-225.

Department of Health, 2010. Confident Communities, Brighter Futures, a framework for developing well-being. Department of Health, London.

Department of Health, 2011. No Health Without Mental Health, a cross-government mental health outcomes strategy for people of all ages. Department of Health, London.

Ditton, J., Chadee, D., Farrall, S., Gilchrist, E., Bannister, J., 2004. From imitation to intimidation. British Journal of Criminology 44, 595-610.

Dixon-Woods, M., Agarwal, S., Young, B., Jones, D., Sutton, A., 2004. Integrative Approaches to Qualitative and Quantitative Evidence. Health Development Agency, London.

Dixon-Woods, M., Cavers, D., Agarwal, S., Annandale, E., Arthur, A., Harvey, J., Hsu, R., Katbamna, S., Olsen, R., Smith, L., Riley, R., Sutton, A.J., 2006. Conducting a critical interpretive synthesis of the literature on access to healthcare by vulnerable groups. BMC Medical Research Methodolology 6, 35.

Eck, J., 1998. Preventing crime at places. In: Sherman, L., Gottfredson, D. MacKenzie, D., Eck, J., Reuter, P., Bushway, S. (Eds.), Preventing Crime: What Works, What Doesn't, What's Promising. US National Institute of Justice, Washington DC

Elchardus, M., De Groof, S., Smits, W., 2008. Rational fear or represented malaise: a crucial test of two paradigms explaining fear of crime. Sociological Perspectives 51, 453-471.

Ellaway, A., Macintyre, S., 1998. Does housing tenure predict health in the UK because it exposes people to different levels of housing related hazards in the home or its surroundings? Health and Place 4, 141-150.

European Crime Prevention Network, 2004. A Review of Scientifically Evaluated Good Practices for Reducing Feelings of Insecurity or Fear of Crime in the EU Member States. European Commission Directorate-General for Freedom, Security and Justice, Brussels.

Evans, G.W., 2003. The built environment and mental health. Journal of Urban Health 80, 536-555.

Fanslow, J., Robinson, E., 2004. Violence against women in New Zealand: prevalence and health consequences. New Zealand Medical Journal 117, U1173.

Farrall, S., Bannister, J.O.N., Ditton, J., Gilchrist, E., 1997. Questioning the measurement of the 'fear of crime': findings from a major methodological study. British Journal of Criminology 37, 658-679.

Farrall, S., Gray, E., Jackson, J., 2007. Theorising the Fear of Crime: The Cultural and Social Significance of Insecurities about Crime. Experience and Expression in the Fear of Crime Working Paper 5. Keele University, Keele, \& LSE, London.

Farrall, S., Jackson, J., Gray, E., 2009. Social Order and the Fear of Crime in Contemporary Times. Oxford University Press, Oxford

Foster, S., Giles-Corti, B., 2008. The built environment, neighborhood crime and constrained physical activity: an exploration of inconsistent findings. Preventive Medicine 47, 241-251.

Fowler, P.J., Tompsett, C.J., Braciszewski, J.M., Jacques-Tiura, A.J., Baltes, B.B., 2009. Community violence: a meta-analysis on the effect of exposure and mental health outcomes of children and adolescents. Development and Psychopathology 21, 227-259.

Franklin, T.W., Franklin, C.A., Fearn, N.E., 2008. A multilevel analysis of the vulnerability, disorder, and social integration models of fear of crime. Social Justice Research 21, 204-227.

Friedrich, E., Hillier, B., Chiaradia, A., 2009. Anti-social behaviour and urban configuration: using space syntax to understand spatial patterns of socioenvironmental disorder. In: Koch, D., Marcus, L., Steen, J. (Eds.), Proceedings of the 7th International Space Syntax Symposium. KTH, Stockholm, p. 34.

Garofalo, J., Laub, J., 1978. The fear of crime: broadening our perspective. Victimology 3, 242-253.

Geronimus, A.T., 1992. The weathering hypothesis and the health of AfricanAmerican women and infants: evidence and speculations. Ethnicity and Disease 2, 207-221.

Geronimus, A.T., Hicken, M., Keene, D., Bound, J., 2006. “Weathering” and age patterns of allostatic load scores among blacks and whites in the United States. American Journal of Public Health 96, 826-833.

Gibson, C.L., Zhao, J., Lovrich, N.P., Gaffney, M.J., 2002. Social integration, individual perceptions of collective efficacy, and fear of crime in three cities. Justice Quarterly 19, 537-564.

Gómez, J.E., Johnson, B.A., Selva, M., Sallis, J.F., 2004. Violent crime and outdoor physical activity among inner-city youth. Preventive Medicine 39, 876-881.

Green, G., Gilbertson, J.M., Grimsley, M.F.J., 2002. Fear of crime and health in residential tower blocks: a case study in Liverpool, UK. European Journal of Public Health 12, 10-15.
Hale, C., 1996. Fear of crime: a review of the literature. International Review of Victimology 4, 79-150.

Halpern, D., 1995. Mental Health and the Built Environment: More Than Bricks and Mortar?. Taylor \& Francis, Abingdon.

Harcourt, B.E., Ludwig, J., 2006. Broken Windows: New Evidence from New York City and a Five-City Social Experiment. University of Chicago Law Review 73, $271-320$.

Herrman, H., Saxena, S., Moodie, R., 2005. Promoting Mental Health: Concepts, Emerging Evidence, Practice. World Health Organisation, Geneva.

Hillier, B., Sahbaz, O., 2007. Beyond hot spots: using space syntax to understand dispersed patterns of crime risk in the built environment. Paper presented at the Conference on Crime Analysis, Institute of Pure and Applied Mathematics, Los Angeles, January 2007.

Hinkle, J.C., Weisburd, D., 2008. The irony of broken windows policing: a microplace study of the relationship between disorder, focused police crackdowns and fear of crime. Journal of Criminal Justice 36, 503-512.

Hirschfield, A., 2004. The health impact assessment of crime prevention. In: Kemm, J., Parry., J., Palmer, S. (Eds.), Health Impact Assessment: Concepts, Theory, Techniques, and Applications. Oxford University Press, Oxford.

Home Office, 2012. Crime in England and Wales: Quarterly Update to September 2011. Home Office, London.

Hope, T., Hough, M., 1988. Area, crime and incivilities: a profile from the British Crime Survey. In: Hope, T., Shaw, M. (Eds.), Communities and Crime Reduction. HMSO, London, pp. 30-47.

Hummelsheim, D., Hirtenlehner, H., Jackson, J., Oberwittler, D., 2011. Social insecurities and fear of crime: a cross-national study on the impact of welfare state policies on crime-related anxieties. European Sociological Review 27 327-345.

Humpel, N., Owen, N., Leslie, E., 2002. Environmental factors associated with adults' participation in physical activity: a review. American Journal of Preventive Medicine 22, 188-199.

Jackson, J., 2006. Introducing fear of crime to risk research. Risk Analysis 26 253-264

Jackson, J., 2009. A psychological perspective on vulnerability in the fear of crime Psychology, Crime and Law 15, 365-390.

Jackson, J., Stafford, M., 2009. Public health and fear of crime: a prospective cohort study. British Journal of Criminology 49, 832-847.

Jackson, J., Gray, E., 2010. Functional fear and public insecurities about crime. British Journal of Criminology 50, 1-22.

Jenkins, R., Meltzer, H., Jones, P.B., Brugha, T., Bebbington, P., Farrell, M., Crepaz Keay, D., Knapp, M., 2008. Foresight Mental Capital and Wellbeing Project. Mental health: Future Challenges. The Government Office for Science, London.

Johnson, S.L., Solomon, B.S., Shields, W.C., McDonald, E.M., McKenzie, L.B., Gielen, A.C., 2009. Neighborhood violence and its association with mothers' health: assessing the relative importance of perceived safety and exposure to violence. Journal of Urban Health 86, 538-550.

Kanan, J.W., Pruitt, M.V., 2002. Modeling fear of crime and perceived victimization risk: the (in)significance of neighborhood integration. Sociological Inquiry 72 , 527-548.

Keleher, H., Armstrong, R., 2005. Evidence-based Mental Health Promotion Resource. Department of Human Services and VicHealth, Melbourne.

Kitchen, P., Williams, A., 2010. Quality of life and perceptions of crime in Saskatoon, Canada. Social Indicators Research 95, 33-61.

LaGrange, R.L., Ferraro, K.F., Supancic, M., 1992. Perceived risk and fear of crime: role of social and physical incivilities. Journal of Research in Crime and Delinquency 29, 311-334.

Lewis, D.A., Maxfield, M.G., 1980. Fear in the neighborhoods: an investigation of the impact of crime. Journal of Research in Crime and Delinquency 17, $160-189$

Liska, A.E., Sanchirico, A., Reed, M.D., 1988. Fear of crime and constrained behavior: specifying and estimating a reciprocal effects model. Social Forces $66,827-837$

Loukaitou-Sideris, A., Eck, J.E., 2007. Crime prevention and active living. American Journal of Health Promotion 21, 380-389.

Lupton, D., Tulloch, J., 1999. Theorizing fear of crime: beyond the rational/ irrational opposition. British Journal of Sociology 50, 507-523.

Maniglio, R., 2009. Severe mental illness and criminal victimization: a systematic review. Acta Psychiatrica Scandinavica 119, 180-191.

McCabe, A., Wine, J., 1997. Framing the Debate: The Impact of Crime on Public Health. Public Health Alliance, Birmingham.

McDonald, N.C., 2008. The effect of objectively measured crime on walking in minority adults. American Journal of Health Promotion 22, 433-436.

McManus, J., Mullett, D., 2001. Better Health, Lower Crime: A Briefing for the NHS and Partner Agencies. Nacro Crime and Social Policy Section, London.

McNeill, L.H., Kreuter, M.W., Subramanian, S.V., 2006. Social environment and physical activity: a review of concepts and evidence. Social Science and Medicine 63, 1011-1022.

Messer, L., Kaufman, J., Dole, N., Herring, A., Laraia, B., 2006. Violent crime exposure classification and adverse birth outcomes: a geographically-defined cohort study. International Journal of Health Geographics 5, 22.

Moon, D., Walker, A., Murphy, R., Flatley, J., Parfrement-Hopkins, J., Hall, P., 2009. Perceptions of Crime and Anti-Social Behaviour: Findings from the 2008/09 British Crime Survey. Home Office, London.

Newman, O., Franck, K.A., 1982. The effects of building size on personal crime and fear of crime. Population and Environment 5, 203-220. 
Normoyle, J.B., Foley, J.M., 1988. The defensible space model of fear and elderly public housing residents. Environment and Behavior 20, 50-74.

Norris, F.H., Kaniasty, K., 1994. Psychological distress following criminal victimization in the general population: cross-sectional, longitudinal, and prospective analyses. Journal of Consulting and Clinical Psychology 62, 111-123.

Northridge, M.E., Sclar, E.D., Biswas, P., 2003. Sorting out the connections between the built environment and health: a conceptual framework for navigating pathways and planning healthy cities. Journal of Urban Health 80, 556-568.

O'Campo, P., Salmon, C., Burke, J., 2009. Neighbourhoods and mental well-being: what are the pathways? Health and Place 15, 56-68.

Pain, R., 1997. Social geographies of women's fear of crime. Transactions of the Institute of British Geographers 22, 231-244.

Pain, R., 2000. Place, social relations and the fear of crime: a review. Progress in Human Geography 24, 365-387.

Pawson, R., Greenhalgh, T., Harvey, G., Walshe, K., 2004. Realist Synthesis: An Introduction. University of Manchester, Manchester.

Perkins, D., Taylor, R., 1996. Ecological assessments of community disorder: their relationship to fear of crime and theoretical implications. American Journal of Community Psychology 24, 63-107.

Pidgeon, N.F., Kasperson, R.E., 2003. The Social Amplification of Risk. Cambridge University Press, Cambridge.

Popova, S., Giesbrecht, N., Bekmuradov, D., Patra, J., 2009. Hours and days of sale and density of alcohol outlets: impacts on alcohol consumption and damage: a systematic review. Alcohol and Alcoholism 44, 500-516.

Riger, S., LeBailly, R.K., Gordon, M.T., 1981. Community ties and urbanites' fear of crime: an ecological investigation. American Journal of Community Psychology $9,653-665$.

Roberts, B., Stickley, A., Petticrew, M., McKee, M., 2009. The influence of concern about crime on levels of psychological distress in the former Soviet Union. Journal of Epidemiology and Community Health 66, 433-439.

Robinson, F., Keithley, J., 2000. The impacts of crime on health and health services: a literature review. Health, Risk and Society 2, 253-266.

Robinson, J.B., Lawton, B.A., Taylor, R.B., Perkins, D.D., 2003. Multilevel longitudina impacts of incivilities: fear of crime, expected safety, and block satisfaction. Journal of Quantitative Criminology 19, 237-274.

Robinson, M.B., 1999. The theoretical development of 'CPTED': 25 years of responses to C. Ray Jeffery. Advances in Criminological Theory 8, 427-462.

Roman, C., Chalfin, A., 2008. Fear of walking outdoors: a multilevel ecologic analysis of crime and disorder. American Journal of Preventive Medicine 34, 306-312.

Ross, C.E., 1993. Fear of victimization and health. Journal of Quantitative Criminology 9, 159-175.

Ross, C.E., Jang, S.J., 2000. Neighborhood disorder, fear, and mistrust: the buffering role of social ties with neighbors. American Journal of Community Psychology $28,401-420$.

Ross, C.E., Mirowsky, J., 2001. Neighborhood disadvantage, disorder, and health Journal of Health and Social Behavior 42, 258-276

Rountree, P.W., Land, K.C., 1996. Perceived risk versus fear of crime: empirica evidence of conceptually distinct reactions in survey data. Social Forces 74 1353-1376.

Russo, S., Roccato, M., 2010. How long does victimization foster fear of crime? A longitudinal study. Journal of Community Psychology 38, 960-974.

Sacco, V.F., 1993. Social support and the fear of crime. Canadian Journal of Criminology 35, 187-196.

Saelens, B.E., Handy, S.L., 2008. Built environment correlates of walking: a review. Medicine and Science in Sports and Exercise 40, S550-S566.

Scarborough, B.K., Like-Haislip, T.Z., Novak, K.J., Lucas, W.L., Alarid, L.F., 2010. Assessing the relationship between individual characteristics, neighborhood context, and fear of crime. Journal of Criminal Justice 38, 819-826.

Schneider, R.H., Kitchen, T., 2007. Crime Prevention and the Built Environment. Routledge, Abingdon.
Shepherd, J., 2007. Preventing alcohol-related violence: a public health approach. Criminal Behaviour and Mental Health 17, 250-264.

Shields, G., King, W., Fulks, S., Fallon, L.F., 2003. Determinants of perceived safety among the elderly: an exploratory study. Journal of Gerontological Social Work 38, 73-83.

Skogan, W., 1986. Fear of crime and neighborhood change. Crime and Justice 8 , 203-229.

Spalek, B., 2008. Communities, Identities and Crime. Policy, Bristol.

Sparks, R., 1992. Reason and unreason in left realism: Some problems in the constitution of the fear of crime. In: Matthews, R., Young, J. (Eds.), Issues in Realist Criminology. Sage, London.

Stafford, M., Chandola, T., Marmot, M., 2007. Association between fear of crime and mental health and physical functioning. American Journal of Public Health 97, 2076-2081.

Stanko, E.A., 1997. Safety talk: conceptualizing women's risk assessment as a 'technology of the soul'. Theoretical Criminology 1, 479-499.

Stiglitz, J.E., Sen, A., Fitoussi, J.-P., 2009. Report by the Commission on the Measurement of Economic Performance and Social Progress. Commission on the Measurement of Economic Performance and Social Progress, Paris.

Sundquist, K., Theobald, H., Yang, M., Li, X., Johansson, S.E., Sundquist, J., 2006. Neighborhood violent crime and unemployment increase the risk of coronary heart disease: a multilevel study in an urban setting. Social Science and Medicine 62, 2061-2071.

Taylor, I., Jamieson, R., 1998. Fear of crime and fear of falling: English anxieties approaching the millennium. European Journal of Sociology 39, $149-175$.

Taylor, R., 2002. Crime prevention through environmental design (CPTED): yes, no, maybe, unknowable, and all of the above. In: Bechtel, R., Churchman, A. (Eds.), Handbook of Environmental Psychology. Wiley, New York.

Taylor, R.B., 1995. Responses to Disorder: Relative Impacts of Neighborhood Structure, Crime, and Physical Deterioration on Residents and Business Personnel. Office of Justice Programs, National Institute of Justice, Washington DC.

Taylor, R.B., Hale, M., 1986. Testing alternative models of fear of crime. Journal of Criminal Law and Criminology 77, 151-189.

Teplin, L.A., McClelland, G.M., Abram, K.M., Weiner, D.A., 2005. Crime victimization in adults with severe mental illness: comparison with the National Crime Victimization Survey. Archives of General Psychiatry 62, 911-921.

Tversky, A., Kahneman, D., 1974. Judgment under uncertainty: heuristics and biases. Science 185, 1124-1131.

Valentine, G., 1989. Women's Fear of Male Violence in Public Space: A Spatial Expression of Patriarchy. Ph.D. Thesis. University of Reading.

Vanderveen, G., 2006. Interpreting Fear, Crime, Risk and Unsafety. Boom Juridische Uitgevers, The Hague.

Walklate, S., 2007. Imagining the Victim of Crime Open University Press, Maidenhead.

Welsh, B., Farrington, D., 2008a. Effects of closed circuit television surveillance on crime. Campbell Systematic Reviews, 17.

Welsh, B., Farrington, D., 2008b. Effects of improved street lighting on crime. Campbell Systematic Reviews, 13.

White, M., Kasl, S.V., Zahner, G.E.P., Will, J.C., 1987. Perceived crime in the neighborhood and mental health of women and children. Environment and Behavior 19, 588-613.

Whitley, R., Prince, M., 2005. Fear of crime, mobility and mental health in inner-city London, UK. Social Science and Medicine 61, 1678-1688.

Wilkinson, R.G., Kawachi, I., Kennedy, B.P., 1998. Mortality, the social environment, crime and violence. Sociology of Health and Illness 20, 578-597.

Wilson, J.Q., Kelling, G.L., 1982. The police and neighborhood safety: broken windows. Atlantic Monthly 127, 29-38.

Wyant, B.R., 2008. Multilevel impacts of perceived incivilities and perceptions of crime risk on fear of crime. Journal of Research in Crime and Delinquency 45 39-64. 